\title{
Why Is There Philosophy of Mathematics at All?
}

\author{
Reviewed by John P. Burgess
}

\author{
Why Is There Philosophy of Mathematics at All? \\ Ian Hacking \\ Cambridge, 2014, $x v+290 p p$. \\ US\$80.00 (hardcover), US\$27.99 (paperback) \\ ISBN 978-1-107-05017-4, 978-1-107-65815-8
}

In his latest book, the noted philosopher of science Ian Hacking turns his attention to mathematics, a long-standing interest of his heretofore seldom indulged. His previous work, though it hasn't always been universally found convincing, has been unfailingly provocative. The present work fits the pattern.

Some mathematicians seeing the title of Hacking's latest book may read it as meaning something like, "Why can't we just get rid of philosophy of mathematics?" asked in a tone of voice suggesting that it would be a very good thing if we could. After all, did not Hilbert himself announce, speaking of foundational questions, that what he wanted to do with them was to get rid of them once and for all [einfürallemal aus der Welt zu schaffen]? But this is not what is intended. Hacking doesn't think philosophy of mathematics will ever go away for good, be got rid of once and for all, and he genuinely means to ask why this is so: What is it about mathematics that historically has kept drawing philosophers back to it time and again?

The answer suggested is that there are two factors at work. One is the experience of following a compelling proof. The seeming inevitability of the conclusion, the feeling that it is not something one is free to take or leave as one chooses, Hacking cites as an ultimate motivation behind philosophies that affirm the independent reality of a realm of mathematical facts, from Plato to Hardy [3]. The other factor is the observation that mathematical

John P. Burgess is professor of philosophy (and associated faculty of mathematics) at Princeton University. His email address is jburgess@princeton. edu.

DOI: http://dx.doi.org/10.1090/noti1189 desk work again and again proves useful in dealing with the world outside the mathematician's office. How by just sitting and thinking we (or some of us) can arrive at results applicable to the world around us has puzzled thinkers from Kant to Wigner [4].

The two features are separate. That results should prove applicable to the physical universe even though they were obtained by pure desk work, without controlled experimentation on or systematic observation of the material world, can be surprising even if what the desk work produces is not compelling deductive proofs but "only" suggestive heuristic arguments. And with the two factors being separate, the material in the book is divided into two more or less separate parts, though with a lot of back and forth between them: one devoted to proof, the other to applications.

Neither the part about proof nor the part about applications is concerned only with their role in perennially drawing the attention of philosophers to mathematics. And, beyond the general division into these two broad topics, the book is rather loosely organized and digressive, not to say rambling, in a way that makes it quite impossible for the reviewer to summarize its contents in an even halfway adequate fashion. The analytical table of contents goes on for six pages, and there is nothing I would leave out, but this means that even to list the topics addressed would take up more space than is reasonable for a review.

One thing just leads to another: If a philosophical view is stated, some mathematical example will be wanted to illustrate it, but then at least an informal explanation of the key concepts in the example will be wanted also, and perhaps a capsule bio of the author or authors of the relevant result or results, and even perhaps in cases where they 
have won prizes something by way of description of the prizes and who established or who awards them, and so on. As a result, in the index one finds Fermat and the Fields Institute, formalism and Foucault, the four-color problem, and Frege and Freud all rubbing shoulders.

\section{Not Philosophy but about Philosophy}

Now it is one thing to write about a field and another to work in it. Hacking asserts early and emphatically that his is a book about philosophy of mathematics, not a work of philosophy of mathematics. He is indeed quite reticent about his own philosophical views, preferring to survey those of others. And the book is wholly free of philosophical polemics: Hacking manages to find something nice to say about almost every writer he discusses or even just mentions in passing, even writers who disagree profoundly with each other, and even writers who disagree profoundly with the views with which Hacking shows himself most sympathetic. (Conflict of interest disclosure: This includes the present reviewer.)

And while Hacking has quite a bit to say about important figures in the history of philosophy and to a lesser extent of mathematics, he also avoids scholarly controversies over the interpretation of the thought of historical figures. Thus he frequently quotes one of his favorites, Ludwig Wittgenstein, about the exegesis of whose cryptic works there have notoriously been very bitter controversies, but cheerfully says that it doesn't matter to him if he has got Wittgenstein right, though he thinks he has. For what it is worth I am mostly inclined to agree, though I am struck by Hacking's omission of certain of Wittgenstein's dicta that if quoted might make the philosopher seem a less sympathetic figure to mathematicians. Try this one (directed against Hardy): “...what a mathematician is inclined to say about the objectivity and reality of mathematical facts, is not a philosophy of mathematics, but something for philosophical treatment...like the treatment of an illness" ([6], 254-5). Or this one (directed against Hilbert on Cantor's paradise): "Philosophical clarity will have the same effect on the growth of mathematics as sunlight has on the growth of potato shoots. (In a dark cellar they grow yards long)" ([5], 381).

More importantly, while a contrast between what Hacking calls "cartesian" and "leibnizian" proofs or conceptions of proof runs through much of his discussion, he spells the labels with a small cee and el by way of indicating that he's not especially concerned to defend any claims about the exact content of the thought of the historical Descartes and Leibniz.

One respect, apart from its livelier style, in which Hacking's book differs from conventional philosophical writing about mathematics is that an enormous amount of work goes into gathering food for thought but much less into boiling it down, chewing it over, and digesting it. For instance, the material on applications goes on at surprising length and depth about etymological issues (when did the expression "mixed mathematics" give way to "applied mathematics"?) and sociological ones (how did the organization of universities into departments in the nineteenth century differ between Britain and Germany?), but it wasn't clear to me what we are supposed to make of all this, fun as it was to read about.

The material on proof also shows a tendency to give priority to information gathering over critical analysis. This is perhaps especially so in connection with the cartesian/leibnizian distinction. It is used as a peg on which to hang the discussion of various issues and episodes and personalities, but the kind of questions that a conventional philosopher of mathematics would feel compelled to address in connection with such a distinction are just not gone into. To cite just one crucial issue: are the various rough characterizations offered of "cartesian" (or "leibnizian") proof equivalent, all pointing towards the same feature? In other words, do we have one distinction here, or are several being run together?

I suspect the latter. Hacking begins by noting that Descartes speaks (though as Hacking significantly admits, not in his mathematical writings) of getting an entire proof in the mind all at once. Hacking doesn't, however, mention why Descartes needs such a notion in his philosophical system. Descartes, towards the ultimate aim of arguing that all knowledge depends on knowledge of God, suggests that the conclusions of an atheist mathematician or any conclusion arrived at by a series of steps can be rendered doubtful by the reflection that maybe a tricky demon was just making it seem that one step followed another. Descartes has an argument why we can't really be deceived by such a tricky demon (the main consideration being that there is a God who would prevent it), but that argument itself consists of a series of steps and so presumably can be rendered doubtful: maybe the tricky demon's trickiest trick is to trick Descartes into believing there is no tricky demon. Only if Descartes can see the whole argument in a flash and not as a succession of steps, if he can get the entire proof into his mind all at the same time, can he be freed from the possibility of having his conclusions rendered doubtful.

But Hacking's notion of "cartesian proof" slides from this first characterization, as a proof that one can get the entirety into one's mind all at once, to a different characterization, as a proof that does not merely convince us that a result is true but explain to us why the result is true. This is a distinction about which, in the last decades, there has been a great deal of discussion by philosophers of mathematics, especially those who identify themselves 
as "philosophers of mathematical practice," with rather meager and inconclusive results (a fact that should hardly surprise Hacking, familiar as he must be with how intense philosophical investigation of "scientific explanation" in theoretical physics a couple of decades back led to similarly meager and inconclusive results). And needless to say there are many quotable things mathematicians have said about such a distinction at one time or another too, not all by any means pointing in the same direction. But what does a proof's being explanatory have to do with our being able to get the entire proof into the mind all at once?

There are lots of proofs of mathematical propositions $p$ that one could say explain why $p$ and don't just convince that $p$. But I don't find myself able in any interesting case to get the entirety of such a proof into my mind all at once, to see the proof as a single step rather than a succession. Hacking cites Littlewood's version of the proof that there can be no decomposition of a cube into cubes all of unequal size, which appears as an epigraph to the book. I myself don't find it easy to take this in as a single step rather than a succession of several-to see in a flash why the result is true, which would presumably include seeing why the same argument doesn't work one dimension down to show that there is no decomposition of a square into squares of unequal size-especially when one fills in the reasoning needed to establish a lemma that Littlewood simply calls obvious. Well, perhaps my mind is just too small for this to fit in all at once. One of Hacking's more amusing, and only too true, observations about the experience of compelling proofs is that most people don't have it.

\section{Glitter}

If Hacking's approach does not stop to carry out the kind of critical analysis that would be needed to establish, say, that in speaking of "cartesian" and "leibnizian" proofs one is looking at a clear, univocally characterized dichotomy, my saying so is not a matter of complaining. It is a matter of explaining how what Hacking is doing in writing about philosophy of mathematics differs from working in philosophy of mathematics-how it differs and why it may be more fun. Writing in philosophy of mathematics generally must plod along at a slow and deliberate pace. Writing about philosophy of mathematics can be breezier and take us to more interesting places in less time.

If I did have any complaint, it would not be about the kind of book Hacking has chosen to write but about his tendency, when he wants to illustrate some phenomenon, to pass over homelier examples and go immediately for the most subtle and sophisticated-and recent. Hacking quotes Wittgenstein as warning against being taken in by "glitter": glamorous results can distract one from what is essential in philosophy of mathematics (and not just of mathematics). Hacking himself, as he is not unaware, sometimes runs the risk of being distracted or distracting his readers in just this way.

Let me illustrate this rather abstract remark by a concrete case. In speaking of what moves some mathematicians and philosophers to speak of mathematical reality as being "out there" before we discover it, Hacking slides from talking about compelling proofs to talking about compelling results, even when the proofs are long and laborious. He mentions classification theorems, which are indeed excellent examples. There is nothing like learning that there are exactly $N$ of something or other to encourage the thought that all $N$ of them were "out there" before we found out about them. The five Platonic solids used to be used as an illustrative example in this way. Hacking suggests that, historically important as this example may be, it has become so familiar that we are now blasé about it and need a different example.

He then goes at once for the classification of simple groups. This provides opportunities to mention various interesting people and exotic topics, but there is no hope in a work written at a semipopular level of explaining what, say, John Conway's "monstrous moonshine" actually amounted to or even what specifically a sporadic simple group is. Surely there must be examplestwo-manifolds, perhaps, or nonplanar graphs-less hackneyed than the Platonic solids but less ferociously technical than finite simple groups.

Another very interesting phenomenon Hacking gets into on his way to discussing the extramathematical applicability of mathematics is intramathematical applicability, beginning with Descartes's application of algebra to geometry. That example by now has something in common with the Platonic solids example, namely, a degree of familiarity that makes it unexciting. Again Hacking goes off in the direction of very sophisticated material indeed - the Langlands program, no less-in search of fresher examples and gets into material so complicated that he himself is not sure whether one should speak of applying one field to another or merely of seeing analogies between fields.

Again there are near-to-hand simpler examples of the phenomenon of surprising connections between diverse mathematical specialties that could have been cited instead or as well. There is, to begin with, De Morgan's well-known old story ([1], 284-7) of an encounter with an acquaintance, apparently in the insurance business, in which they were talking of life expectancies and De Morgan cited some actuarial formula, probably related to the normal distribution, involving the symbol $\pi$ for the famous constant, the ratio of circumference to diameter. The reply was, "Oh, my dear friend, that must be a delusion; what can the circle have to do with the numbers alive at the end of a given 
time?" This simple example at least shows clearly the first crucial feature that needs to be mentioned in connection with surprising connections: there isn't going to be any nonmathematical explanation of them.

\section{Summary}

There is much more in the book. I have taken well over two thousand words without really touching on the aspects of the book touted in the publisher's blurb: discussion of the historical question where proof came from, what the distinction is between applied and pure, and the question "What is mathematics?" Any answer to this last is likely to look disappointing after Timothy Gowers's splendid editorial preface to [2], in which he quotes Russell's definition of mathematics and adds that his volume (of 1,000+ pages) is about what Russell's definition leaves out. Hacking gives the question only about thirty-five pages, but he does manage to bring in curious information you won't find in the Gowers volume.
Perhaps I should stop here. But before closing, let me mention one more respect in which Hacking's book about philosophy of mathematics differs from books in philosophy of mathematics: Since it is as far as possible from being one long, connected argument for a distinctive, unifying thesis, the reader can freely dip into it, open it almost anywhere, and start reading with pleasure and profit.

\section{References}

[1] Augustus De Morgan, A Budget of Paradoxes, 2nd ed., vol. 1, Open Court, 1915.

[2] Timothy Gowers (ed.), The Princeton Companion to Mathematics, Princeton University Press, 2008.

[3] G. H. HARDY, A Mathematician's Apology, Cambridge University Press, 1940.

[4] EUGENE WigneR, The unreasonable effectiveness of mathematics in the natural sciences, Communications in Pure and Applied Mathematics 13 (1960), 1-14.

[5] Ludwig Wittgenstein, Philosophical Grammar, ed. Rush Rhees, trans. Anthony Kenney, Blackwell, 1974.

[6] __ Philosophical Investigations, 3rd. ed., trans. G. E. M. Anscombe, Blackwell, 2001.

\section{Film Review}

\section{Ramanujan and the Nature of Genius}

\section{Reviewed by Mark Saul}

The Genius of Srinivasa Ramanujan
Documentary, running time 60:00
Director: Nandan Kudhyadi
Co-Producer: Vigyan Prasar and IISER Pune
Indian DVD-premiere: March, 2013
View movie trailer at: youtube.com/wash?v=uHHI
OTMih7E\&feature=youtu.be

We are not in control of our own minds. Our thoughts, and certainly our feelings, come to us unbidden and unbridled. Attempts to channel either meet with mixed success, and trying to assign causality to the flow of ideas quickly founders on jagged philosophical rocks. We can describe

Mark Saul is Director, Center for Mathematical Talent, Courant Institute. His email address is marksau1@ earth7ink. net.

The author would like to thank, in addition to the people quoted in this article, Steven Krantz for his help.

DOI: http://dx.doi.org/10.1090/noti1183 our thoughts, express our feelings, but we cannot summon them at will.

Nonetheless, thinking and feeling are the central experiences of our lives. And the experience of being a genius, while inaccessible to most of us, is the more intriguing for just that. What is genius? Is it a singular set of mental faculties that some are born with and others are not? Is it the result of upbringing? Of genetics? Of the intervention of a Higher Power? Or perhaps it is a mental illness, a syndrome that renders the sufferer capable of incredible feats of thought, from which the rest of us profit but which keeps the victim personally miserable.

The film The Genius of Srinivasa Ramanujan plays on this intrigue. Wisely avoiding an attempt to analyze the phenomenon that was Ramanujan's mind, it tries rather to take us through the experience of being Ramanujan or close to Ramanujan. We understand much more of Ramanujan's mathematics than we do of the mind that created 
it. And so the film poses more questions than it can answer, and leaves us wanting answers more than before.

The film is structured as a pilgrimage to places in India and England where Ramanujan's life played out. At each station of the pilgrimage, we meet mathematicians who continued Ramanujan's work, people who admired his work, or (in a few scenes) Ramanujan himself, played, often silently, by an actor. For example, we are taken to Ramanujan's birthplace in the town of Erode. Unfortunately, this home is in a dilapidated condition. But then a significant part of the filming is done in Kumbakonam where he grew up, and where he made many great discoveries. Happily the Kumbakonam home is now maintained in excellent condition, after SASTRA University's purchase ${ }^{1}$ of it in 2003.

The film wonderfully evokes the places and times that were the backdrop of Ramanujan's work.

There is no exposition of Ramanujan's mathematics-that is for a different audience. Nor is there a scene-by-scene recounting of his life story, which can be found elsewhere. Rather, the film immerses the viewer in the India of Ramanujan's youth, the England of his all-too-brief adulthood, and the scene of his illness and death. For example, the film brings us Kumar Murty, telling us that creativity does not really stem from rationality or logic. It is, he says, more like an aesthetic experience, more a feeling than a thought. Deep mathematics (we can all relate to this) gives a feeling of intellectual pleasure. Murty's personal note is followed by a scene from Ramanujan's life: not a milestone, not a dramatic event, but Ramanujan talking with an unnamed Indian mathematician, sharing with him the joy of discovery. The mathematics is only briefly described and is not the point. Indeed, the scene begins in Tamil, not English, and so for most of us it is only the inflections of the language, the emotional experience, that is conveyed.

The film leaves unexamined some important aspects of Ramanujan's life. While the mathematical community in India was small and not well developed at the time, a number of Indian mathematicians recognized Ramanujan's gifts and supported him in several ways. And a number of British mathematicians left his letters unanswered. It was part of Hardy's genius that he considered seriously Ramanujan's letter and brought us Ramanujan's mind. But if we take as the subject of the film the experience of the genius, there is a more serious omission, and one that would be difficult to fill. That omission is the experience of struggle,

\footnotetext{
${ }^{1}$ See $\longdiv { \text { src.sastra.edu/index.php?option=com_ } }$ content\&vi ew=artic 1 e\&id=234\&Itemid=345 (accessed September 2014).
}

of hard work, that is central to the professional lives of most, including the geniuses among us. The triumph of understanding is often the sweeter when it is the result of hard work, deep reflection, a struggle towards the light. This is something not widely appreciated by the public. Many think of genius, or even simply intellect, as a gift that is given to some and not to others. Those to whom it is given, in this view, are blessed with facility in understanding and are merely walking along a pleasant path.

Anyone who has worked at mathematics-on almost any level-knows that this view is false. While a genius may find elementary work (which is all most people know of mathematics) easy, she or he will also find it boring until faced with a challenge. The literature on gifted education shows us that the talent of gifted students will fizzle if the students don't find mathematics intriguing. They will turn their minds to more stimulating material in other subjects if we don't offer them what they need in mathematics. A genius is both born and made.

Another important aspect of Ramanujan's life is brought out well in the film: Ramanujan's genius, in a sense, "made itself." He found only little encouragement from his environment and only a bit of mathematical guidance (famously, from Carr's Synopsis). Genius is as fragile as it is powerful. Ramanujan persisted, had faith in himself, knew that his results were valuable, and eventually found the right support in his own strength of character.

So is character an essential element of genius? Certainly. And this observation leads us to deeper questions. The notion that character is fate, found as early as the ancient Greek tragedies, begs an important question: What are the roots of character? How, by what forces, was Ramanujan's indomitable character formed? Family? Culture? Religion? The film does not take a position on this question except to tell us about the goddess of Namakkal, whom Ramanujan thought of as his inspiration. (This is an important element of the film, as a Western audience would probably not otherwise appreciate the religious traditions that were so vivid for Ramanujan. ${ }^{2}$ ) The film gives no answers, but does bring us to ask the questions-enough of a contribution for a 60-minute work of art.

What else contributes to the development of character, including the character of a genius? Happenstance? Well, is it happenstance that but-

\footnotetext{
${ }^{2}$ Krishnaswami Alladi (University of Florida) points out a scene in the film where Ramanujan laughs, saying that he mentions the Goddess of Namakkal as an inspiration only to those who are incapable of understanding his mathematics. (The scene is in the Tamil language.) Alladi notes that this sentiment was not at all typical of Ramanujan, and contradicts other scenes in the film, where Ramanujan's veneration of the Goddess of Namakkal, and that of his family, is emphasized.
} 


\section{HINDUSTAN
BOOK AGENCY}

\section{BASIC ERGODIC THEORY}

THIRD EDITION

M. G. Nadkarni, University of Mumbai, India

This is an introductory text on ergodic theory. The presentation has a slow pace, and the book can be read by anyone with a background in basic measure theory and metric topology.

The third edition has, among other improvements, a new chapter on additional topics that include Liouville's theorem of classical mechanics, the basics of Shannon Entropy and the Kolmogorov-Sinai theorem, and van der Waerden's theorem on arithmetical progressions.

Hindustan Book Agency; 2013; 196 pages; Hardcover; ISBN: 978-9380250-43-4; List US\$48; AMS members US\$38.40; Order code HIN/58

\section{PROBABILITY THEORY}

A FOUNDATIONAL COURSE

R. P. Pakshirajan, University of Mysore, India

This book shares the dictum of J. L. Doob in treating probability theory as a branch of measure theory and establishes this relationship early. Probability measures in product spaces are introduced right at the start as a way of laying the groundwork to later claim the existence of stochastic processes with prescribed finite-dimensional distributions.

Hindustan Book Agency; 2013; 564 pages; Hardcover; ISBN: 978-9380250-44-I; List US\$68; AMS members US\$54.40; Order code HIN/60

\section{ATIYAH-SINGER INDEX THEOREM}

\section{AN INTRODUCTION}

Amiya Mukherjee, Indian Statistical Institute, Calcutta, India

This monograph is a thorough introduction to the Atiyah-Singer index theorem for elliptic operators on compact manifolds without boundary. The main theme is only the classical index theorem and some of its applications, but not the subsequent developments and simplifications of the theory.

Hindustan Book Agency; 2013; 276 pages; Hardcover; ISBN: 978-9380250-54-0; List US\$60; AMS members US\$48; Order code HIN/64

\section{SELECTED PAPERS OF V. S.}

\section{VARADARAJAN}

VOLUMES 2 AND 3

Donald G. Babbitt and Ramesh Gangolli, K. R. Parthasarathy, Indian Statistical Institute, New Delhi, India,

Enrico G. Beltrametti and Gianni Cassinelli, University of Genova, Italy, Rita Fioresi, Università di Bologna, Italy, and Anatoly N. Kochubei, National Academy of Sciences of Ukraine, Kiev, Ukraine, Editors

The current volumes contain the papers on fundamental questions of individual and families of meromorphic differential equations that are treated by a new group theoretic and functional approach; papers on representation theory of Lie groups; papers on foundations of physics, supersymmetry, and P-adic aspects of quantum physical theories; papers on analysis, especially oscillatory integrals, on semi-simple lie groups, their conjugacy classes, and their flag manifolds; and finally, several review articles, both personal and mathematical, on a number of the above topics

Hindustan Book Agency; 2013; 1366 pages; Hardcover; ISBN: 978-9380250-57-I; List US\$165; AMS members US\$132; Order code HIN/65

Publications of Hindustan Book Agency are distributed within the Americas by the American Mathematical Society. Maximum discount of $20 \%$ for all commercial channels.

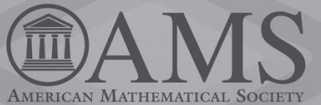

BOOKSTORE
Order Online: Order by Phone: (800)321-4267 (U.S. \& Canada) (401)455-4000 (Worldwide) www.ams.org/bookstore terflies evolved to be so fragile and beautiful? That Shanghai is a great city and not a fishing village? That the dinosaurs died out? Genius, like all these phenomena, requires the right environment, the right nourishment, to flower. Were any one circumstance lacking, we might have had no Ramanujan. Indeed, a potential Ramanujan could now be working as a Nigerian cab driver or an Indonesian bank teller. All we can do is maximize the chances that he or she be found.

As educators, we can begin to think about the elements of the "right" environment for genius. Can we build institutions and structures that encourage its growth? Mathematicians and historians have long remarked on the unreasonably large number of Hungarian mathematicians. Perhaps an examination of that country's history might give us clues. ${ }^{3}$ But probably not a template. No country can arrange to experience another country's historical development. Cultural anthropologists tell us that the phenomenon of diffusion, of one culture borrowing from another, is significantly more complicated.

These are messages for society. But viewing the film is a personal experience. What personal message does this film carry? Will the viewer get the message that he or she will be inspired by Ramanujan? Probably not. And for most of us, such a message would be fatuous. Not many can follow his example with the same results.

So what messages does the film have and for whom? Here are some suggestions. For the student (on almost any level) the film speaks to the joy of discovery, the rewards of hard work, and the experience of mathematical beauty. For the teacher (again, on almost any level) the film brings the message that students have their own thoughts and their own inspirations. There is some merit in the suggestion that a teacher would do well to assume every new student is a Ramanujan-and to be corrected almost every time. The one time in several billion that such an assumption proves correct easily makes up for the myriad times it is wrong. For the parent: A child must follow his or her own path. Ramanujan left school twice because he was so focused on mathematics. His family seems to have swallowed the disappointment. For the mathematician: Your personality and your circumstances are the genesis of your abilities, including the ability to work hard on mathematics, and therefore of your accomplishments.

For everyone: Ramanujan's goddess may not bestow her gifts on all of us. But it behooves us to listen when she speaks. We all have some gifts, in some measure, and we can learn from Ramanujan's story how passing on these gifts can be important to others and satisfying to oneself.

${ }^{3}$ See. for example. www. franktibor. hu/img/kozl/ FRANK. Socia $\% 20$ Construction3.doc, accessed August 2014. 